\title{
Innovative Energy Harvesting Exposition Park of Kaunas Science Island Museum
}

\section{Hariharasubbu Balmoorthy*}

Faculty of Civil Engineering and Architecture, Kaunas University of Technology

Studentu st. 48, LT-51367 Kaunas, Lithuania

\section{Rasa Apanaviciene}

Faculty of Civil Engineering and Architecture, Kaunas University of Technolog

Studentu st. 48, LT-51367 Kaunas, Lithuania

${ }^{*}$ Corresponding author: hariharasubbu.balamoorthy@ktu.edu

\section{Crossuref http://dx.doi.org/10.5755/j01.sace.21.4.19180}

The paper presents a project idea of innovative energy harvesting exposition park that involves utilizing the area around the proposed Science Island museum in the City of Kaunas. The project presents various Energy harvesting structures such as Photovoltaic Geodesic dome, Photovoltaic Trees, Wind Energy Trees, Piezoelectric Rain Farm, Photovoltaic Floors, Luminescent roads, and three alternative Landscape architecture layouts of those structures within the surrounding area of the Science Island museum. The paper covers the energy calculation of those energy harvesting structures and their construction cost analysis. The energy calculations show significant role in powering up the park area, however it does not cover the energy demand of the main building of Science Island museum. The purpose of constructing energy harvesting elements is to demonstrate for the visitors the application of innovative technologies for electric energy generation. The paper concludes that the implementation of these innovative energy-harvesting elements through means of Landscape Architecture not only enhances the aesthetic appearance of the Science Island museum but also provides alternative energy resources for electrical elements inside the park.

Keywords: Landscape Architecture, Luminescent road, Photovoltaics, Piezoelectric, Wind Energy.

Kaunas is the second largest city in Lithuania which boasts a unique mixture of immense cultural heritage that are several centuries old and captivates modern constructions at many places around the city. At the same time, Kaunas is a city of Universities with a large population of the national and international academic community. As a part of the city's commitment to promote the values of Science and Technology, the City council had proposed the construction of a Science Island museum in the Nemunas River Island besides the Žalgiris Sports and Entertainment Arena. With the project itself as monumental work, the area surrounding the museum, which is a green park, has more usefulness with the new plans of the Science Island. This research suggests utilizing the surrounding area of the Island with installation of Photovoltaic (PV) Geodesic Dome, Photovoltaic Trees, Wind Energy Trees, Piezoelectric Rain Farm, Photovoltaic Floors, Luminescent roads. With the increasing scarcity for non-renewable energy resources, construction of renewable energy harvesting structures is in need now more than ever. The main aim of the project is to promote the construction of renewable energy harvesting structures through Landscape architecture, by utilizing the area around the Science Island museum in the Nemunas River Island. The scope of the research work presented within this paper limits to the selection of one of the three different site layouts for the installation of structures, the Energy Calculations of the proposed elements and the construction cost analysis.

\section{Introduction}

Innovative Energy Harvesting Exposition Park of Kaunas Science Island Museum

Received 2017/10/09

Accepted after revision 2017/12/22

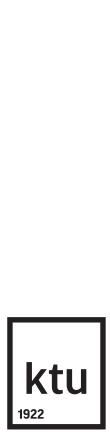

Journal of Sustainable Architecture and Civil Engineering Vol. 4 / No. 21 / 2017 pp. $63-74$ 
Methodology

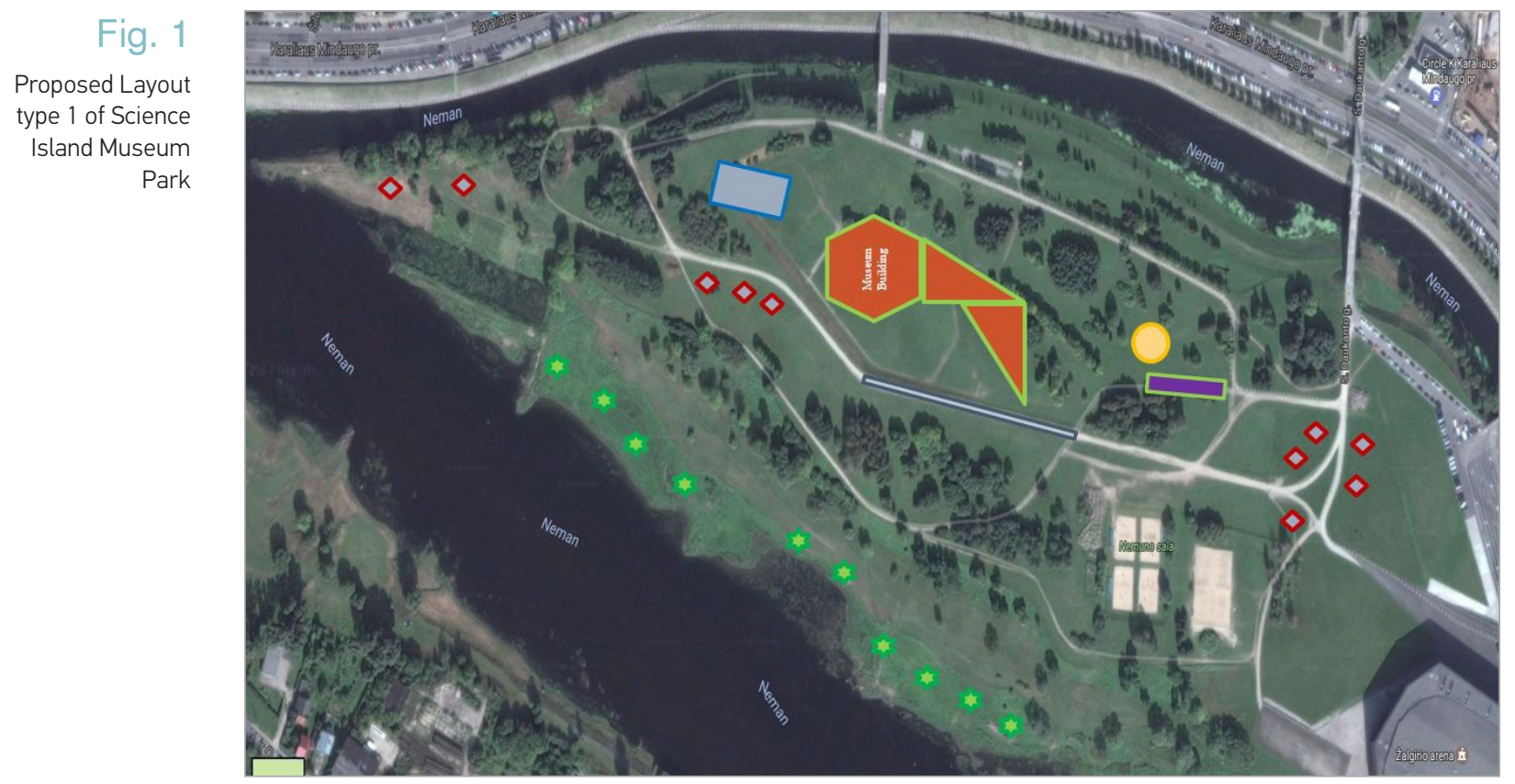

Fig. 2

Proposed Layout type 2 of Science Island Museum Park in the planning stage and no construction works have begun yet. The location of the proposed Science Island museum lies in the island of the Nemunas River that flows in Kaunas. The whole area of the island is approximately $234,624 \mathrm{~m}^{2}$. This calculation is based on the area calculation through GPS satellite tracking by Google Maps and the accuracy of the total land area of the park should be tested in the next stage of project development through Surveying. It should be noted that the area of the park excludes the part of Island with the Žalgiris Sports and Entertainment Arena.

The methodology of planning of the structures as outside architectural elements involves designing three different park layouts which were carried out using Photoshop tools on Google satellite maps as seen in Fig. 1, 2, 3.
The entirety of the proposed Science Island museum at the time of writing this paper is still only

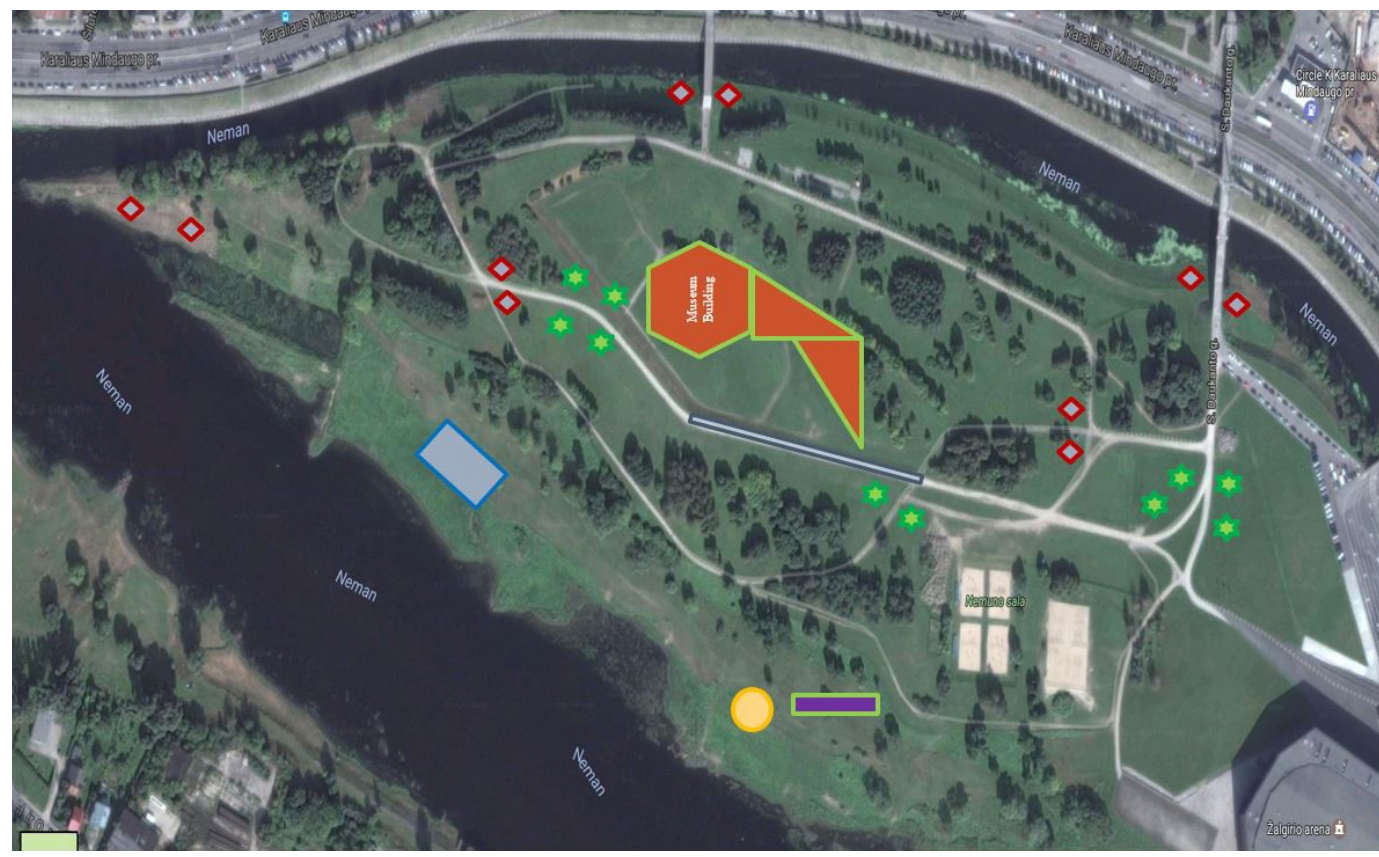




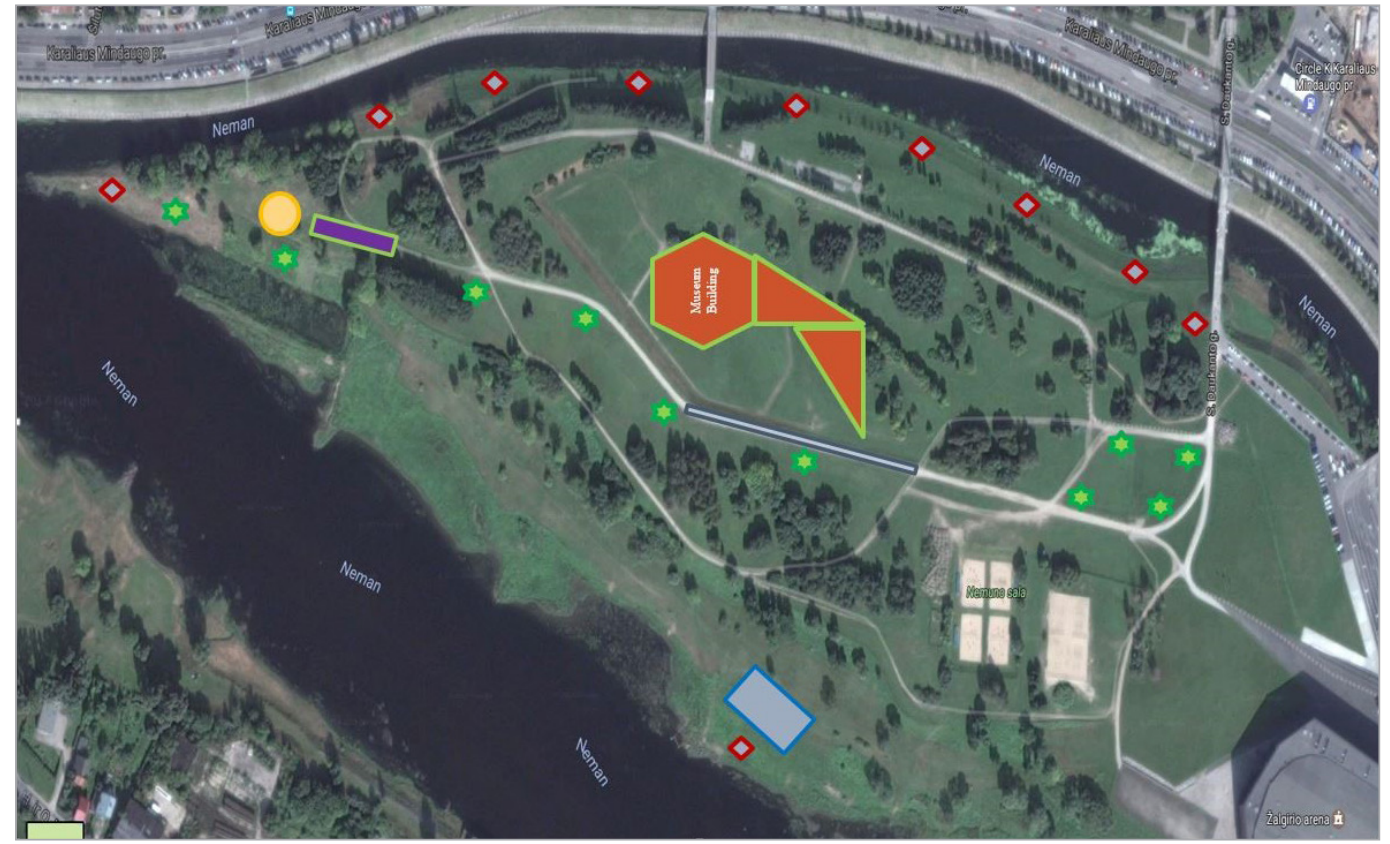

\begin{tabular}{|c|c|c|c|c|c|}
\hline Sl. No & Technology & Element & Description & Quantity & Size \\
\hline 1.1 & \multirow{3}{*}{ Photovoltaics } & & PV Geodesic Dome & 1 & Diameter $10 \mathrm{~m}$; Height $5 \mathrm{~m}$ \\
\hline 1.2 & & 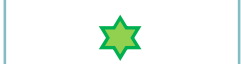 & PV Trees & 10 & Height 4.5 m \\
\hline 1.3 & & = & PV Floor & 1 & $300 \mathrm{~m}^{2}$ \\
\hline 2 & Wind Turbines & & Wind Energy Trees & 10 & Diameter 7.5 m; Height 10 m \\
\hline 3 & Piezoelectrics & & Piezoelectric Rain Farm & 1 & $25 \mathrm{~m}^{2}$ \\
\hline 4 & Chemi-luminscence & & Luminescent road & 1 & $1500 \mathrm{~m}^{2}$ \\
\hline
\end{tabular}

The different energy harvesting structures proposed around the Science Island museum in the Nemunas River Island are shown in Table 1.

\section{Photovoltaic Technology}

\section{Photovoltaic Geodesic}

\section{Dome}

The PV Geodesic Dome will be the main structure of interest outside the main Science museum in the Science Island museum park (Fig. 4).

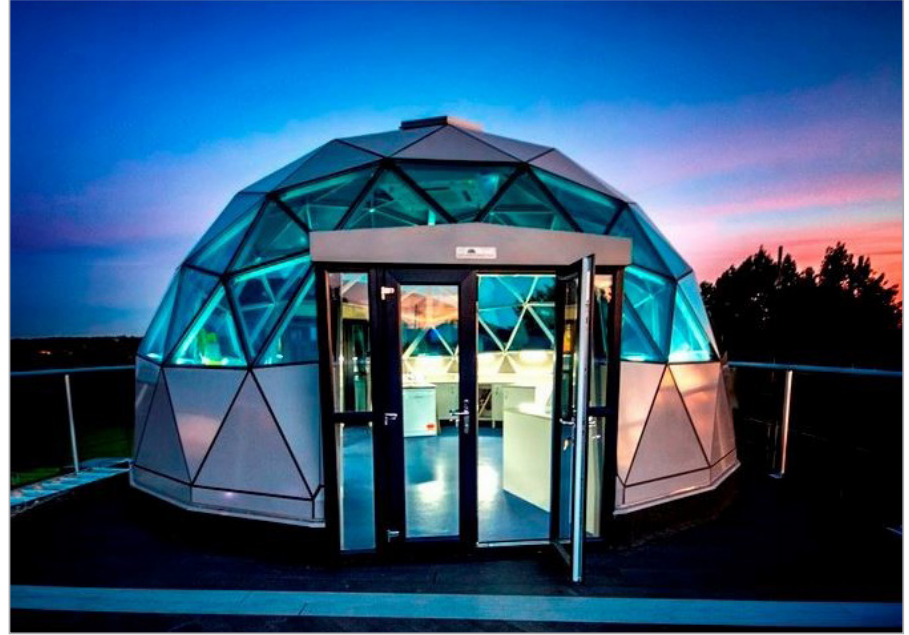

Fig. 3

Proposed Layout type 3 of Science Island Museum Park

Table 1

Description of Labels for Fig. 1, 2, 3

Fig. 4

SOLARDOME ${ }^{\circledR}$ PRO science lab, Watford Grammar School for Girls [Source: Image Retrieved from http://www. solardome.co.uk/gallery/ solardome-pro/] 
The dome is proposed as a structure that shall have permanent exhibition of the PV Energy Technologies, their future for sustainable energy harvesting, etc. The diameter of the dome is planned to be $10 \mathrm{~m}$ in size. Building Integrated Photovoltaic Crystalline Silica panels are installed on the exterior of the Dome. The whole dome will power itself inside and the extra-energy harvested will be sent to the grid. The solar dome aims to promote the energy and social values of harvesting solar energy. (SOLARDOME ${ }^{\circledR}, 2017$ )

\section{Photovoltaic Trees}

The PV Trees are tree like structures with solar panels (Fig. 5). This shall be one of the architectural elements of the landscape architecture of the Science Island museum park area. The total number of trees proposed are 10. Each tree is $3 \mathrm{~m}$ tall and has four PV panels installed. Each tree is fitted with LED lights that illuminate at night. The suggested model uses a self-storage battery, details of which was not provided by the Manufacturer. However, all trees might be connected to the Grid since the energy production varies throughout the year. During the daytime, they only stand as a part of the landscaping architectural elements. The various services provided by the

Fig. 5

3D Graphical model of PV eTree [Source: Image Retrieved from http://sol-logic.com/ etree/]

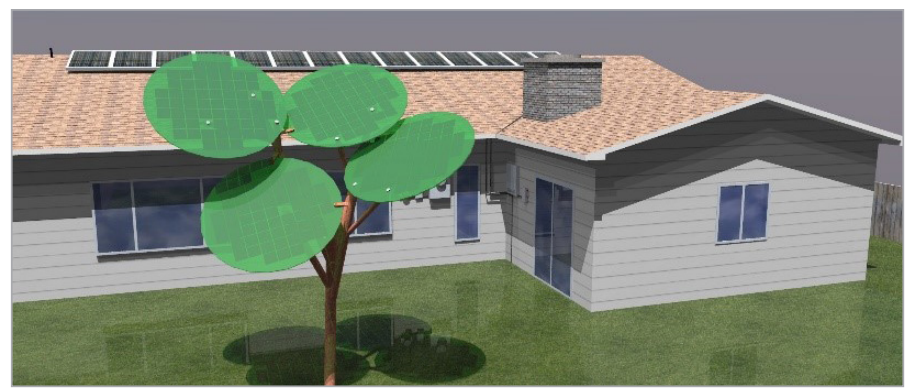
solar tree includes the following (Sologic, 2017):

_ Shaded resting area; - Free Wi-Fi;

- Docking stations for smart phones and other electric devices;

Illumination by night.

\section{Photovoltaic Floor}

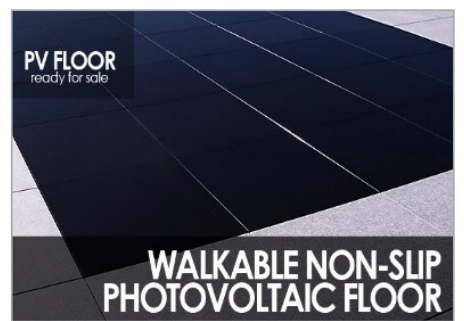

The PV floor panels are designed as walkable floor which is proposed as one of the structures to be installed on one of the pathways leading to the Science Island museum (Fig. 6). The PV floor uses the solar light to generate electricity which is connected to the Grid. The proposed distance of the PV floor is $100 \mathrm{~m}$ with a pavement width of $3 \mathrm{~m}$. This again promotes the use of solar energy harvesting using photovoltaic technology.

\section{Photovoltaic Energy Calculation}

For a PV panel, the energy comes as waves of Photons from the Sun. The light energy is converted into electrical energy. The total power $P_{\text {IN }}$ per area for a given Photon spectrum $\Phi_{0}(\lambda)$ is given by the formula in Eq.1. (Fonash, 2010):

$$
P_{I N}=\int_{\lambda} \frac{h c}{\lambda} \Phi_{0}(\lambda) d \lambda
$$

The methodology for calculating PV Energy output for PV panels involves collecting data on the following:

Solar irradiance;

Tilt of the installation;

Direction of the installation.

For a tilted PV panel, the radiation calculation takes into account three components namely: Direct radiation, Diffuse radiation, Reflected radiation. The overall radiation $E_{\text {Gen }}$ is given by the formula shown in Eq.2 (Mertens, 2014):

$$
E_{\text {Gen }}=E_{\text {Direct_Gen }}+E_{\text {Diffuse_Gen }}+E_{\text {Refl_Gen }}
$$


Where:

$E_{\text {Direct_Gen }}=E_{\text {Direct_H }} \cdot \frac{\sin \left(y_{S}+\beta\right)}{\sin y_{S}}$
$E_{\text {Diffus_Gen }}=E_{\text {Diffus_H } H} \cdot \frac{1}{2} \cdot \cos (1+\beta)$

$$
E_{\text {Refl_Gen }}=E_{G} \cdot \frac{1}{2} \cdot \cos (1+\beta) \cdot A L B
$$

$E_{\text {Direct } H}$ : Direct Radiation on horizontal surface; $E_{\text {Diffus_H }}$ : Diffuse Radiation on horizontal surface; $E_{G}$ : Reflected Radiation on horizontal surface; : Solar altitude angle; : Elevation angle of Solar Generator; ALB: Albedo Value. Usually, for the Solar Radiation calculation, Direct Radiation and Diffuse Radiation are used as they are anisotropic (Fig. 7.a, 7.b). Reflected Radiation is usually not considered as it is isotropic.

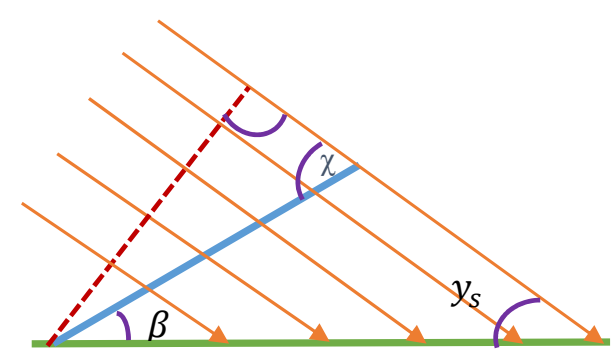

(a)

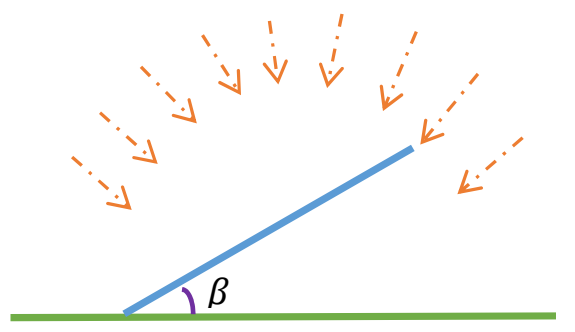

(b)

The formula for calculating the Energy of the Photovoltaic panel as given in Eq.3 (Šúri, Huld, Dunlop, Albuisson, \& L., 2006):

$$
E=365 * P_{k} * r_{p} * H_{h, i}
$$

Where: $E$ - energy (kWh/an); $P_{k}(\mathrm{~kW})$ is the peak power installed; $r_{p}$ is the system performance ratio; $H_{h, i}$ is the monthly or yearly average of daily global irradiation on the horizontal or inclined surface (1025 kWh/m² in Kaunas on horizontal surface) (Lietuvos Energetikos Institutas, 2010).

\section{Wind Energy Trees}

Wind Energy tree mimics the resemblance of a tree with leaves, only the leaves will be rotating wind turbines (Fig. 8). The total number of trees proposed are 10. These trees also shall be a part of the landscape architecture elements of the Science Island museum park. Each tree has 63 leaf-turbines and the design capacity is 4.1 $\mathrm{kW}$, however it can capture up to 5.4 kilowatts of energy at a time and produce around 2,400 kWh annually with an activation threshold of $1.3 \mathrm{~m} / \mathrm{s}$ and power generation from a minimum wind speed of 2 $\mathrm{m} / \mathrm{s}$ (Fig. 9) (Newwind, 2017).

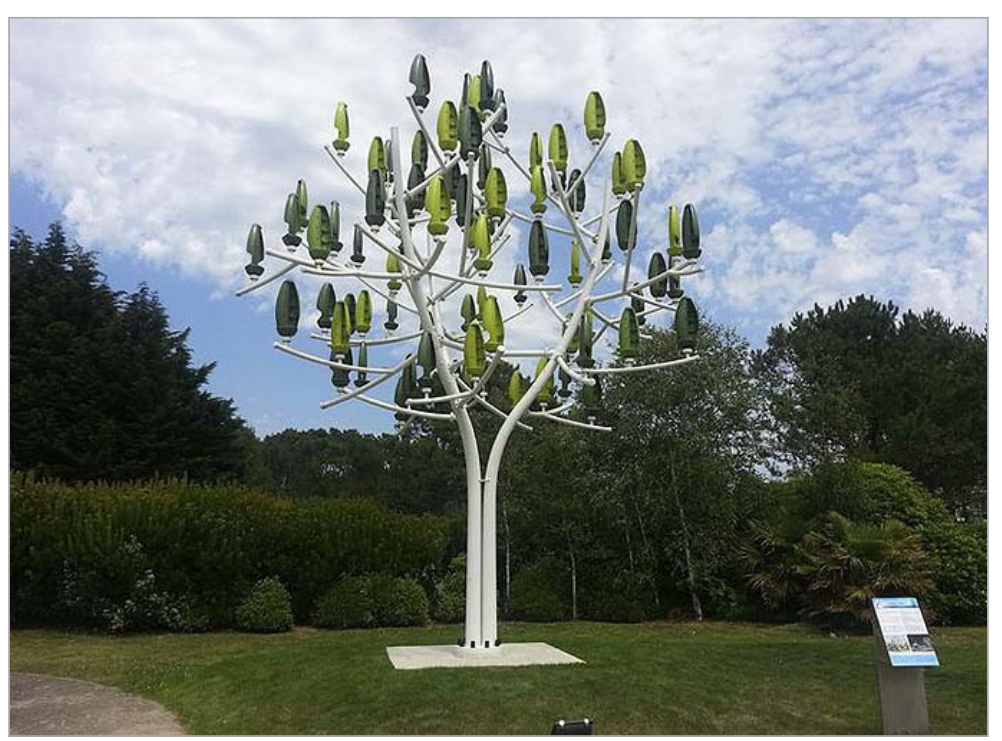

\section{Fig. 7}

(a) Direct Radiation on Tilted Surface [Sources: Image based on picture from (Mertens, 2014, p. 34)]

(b) Diffuse Radiation on Tilted Surface [Sources: Image based on picture from (Mertens, 2014, p. 36)]

Fig. 8

Wind Tree, [Source: Image Retrieved from https:// offgridworld.com/3-1 kwnew-wind-turbine-lookslike-a-tree/] 
Fig. 9

Energy Production details by WindTree [Source: Newwind, 2017]

\section{Wind Energy} Calculation

\section{Fig. 10}

Imagined Urban Field by Designer Anthony

DiMari (Actual design intended for Wind

Energy), [Source: Image retrieved from http://anthonydimari. $\mathrm{com} /$ ]
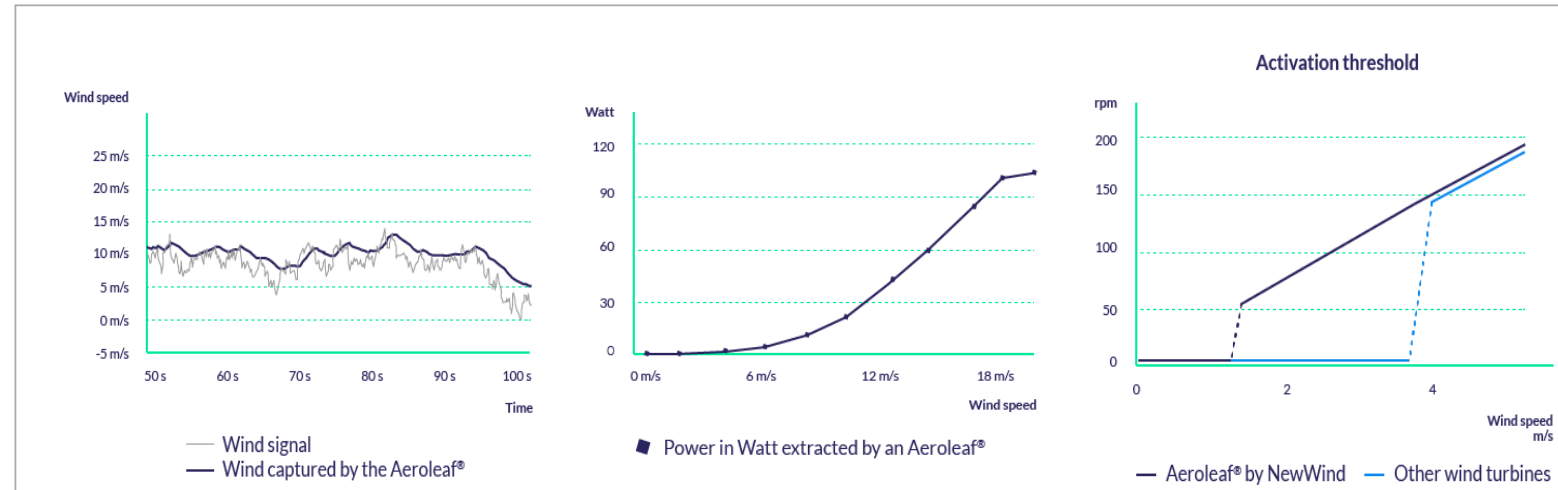

The methodology of the calculation of the wind power with respect to rate of change of energy, involves the formula as given in Eq.4. (The Engineering ToolBox, 2017)

$$
P=\frac{\rho A v^{3}}{2}=\frac{\rho \pi d^{2} v^{3}}{8}
$$

Where: $P$ - power $(\mathrm{W}) ; \rho$ - density of air $\left(\mathrm{kg} / \mathrm{m}^{3}\right) ; A$ wind mill area perpendicular to the wind $\left(\mathrm{m}^{2}\right) ; v$ - wind velocity $(\mathrm{m} / \mathrm{s}) ; \pi-3.14 \ldots ; d$ - wind mill diameter $(\mathrm{m})$.

For any design of wind turbine, the theoretical maximum power efficiency is 0.59 which is the Power coefficient given, $C_{P_{\max }}$ (The Royal Academy of Engineering). However, no wind turbine can operate at the maximum power. $C_{p}$ ranges from $0.35-0.45$. Therefore, the actual wind power is calculated by the formula as shown in Eq.5.

$P=\frac{\rho A v^{3} C p}{2}$

It should be noted that the air density lowers with temperature and altitude. Having said that, the major factor for production of wind power is the velocity of wind. $20 \%$ increase in wind velocity will increase the power generation by 73\% (The Engineering ToolBox, 2017).

\section{Piezoelectric Rain Farm}

This is a separate farm where special structures are installed to harvest energy from rain (Fig. 10).

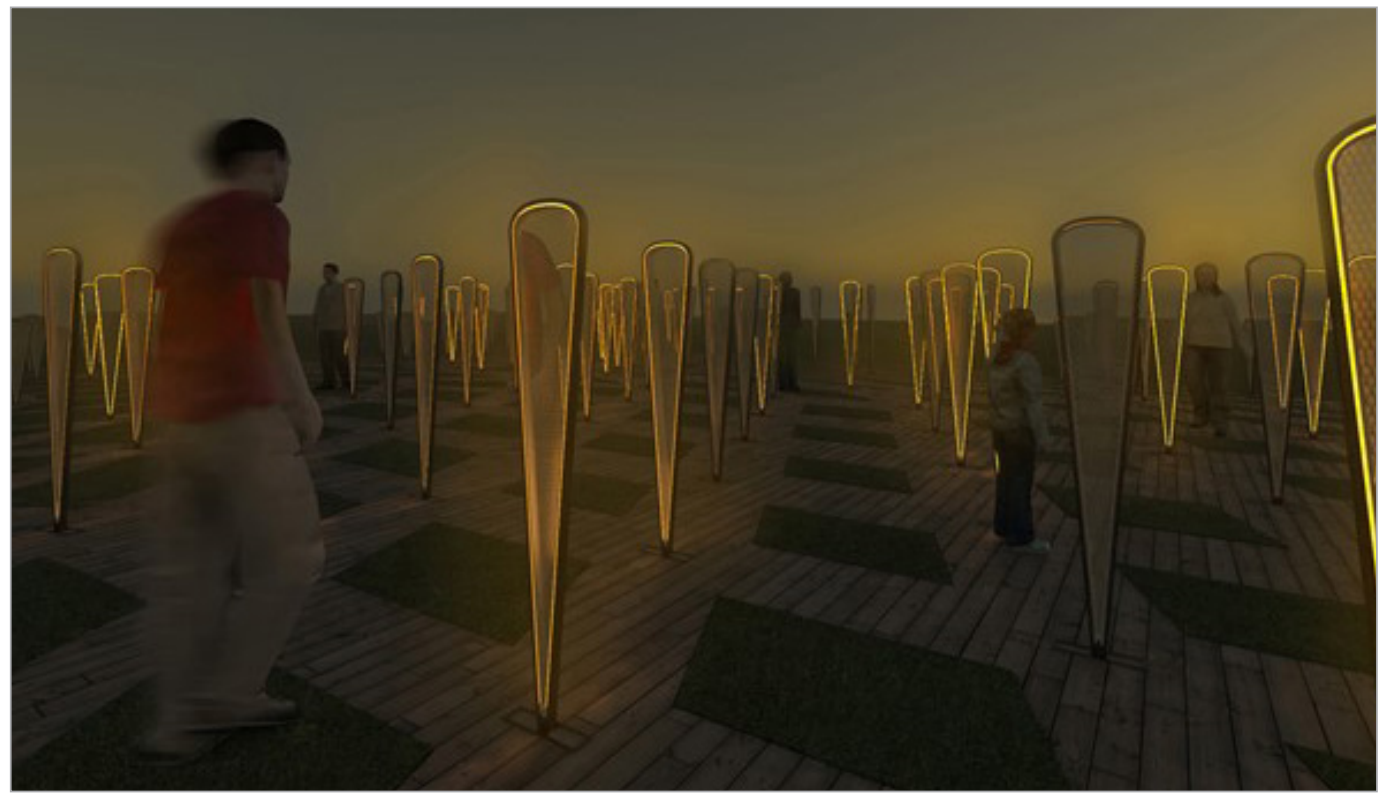


These structures are not marketed and are subjected to a special design. In theory, these structures are covered by piezoelectric elements on the outer side. The rainfall induces the application of mechanical loading on these elements and thereby the electricity is produced as a result of the piezoelectric effect. However, the electricity produced is intended to be a fun lighting for the children to play, since the energy production would be minimal. The Farm will be installed as a monument itself, like that of the solar dome in a separate part of the Science Island museum park.

\section{Luminescent Road}

The proposed concrete pavement road will be $500 \mathrm{~m}$ long with a pavement width of $3 \mathrm{~m}$. It will be the main road leading to the Solar Dome. Safe luminescent aggregates are used on the road surface. These aggregates are not bio-synthesized but are chemically made. These aggregates make the road to glow at dark, thereby the road becomes a self-lighting pathway for the public during the night time (Fig. 11). This promotes the current research on Bioluminescent lighting and the values of their practical applications in the future (Glowee, 2017). The road is designed only for pedestrian walking and not for heavy vehicles.

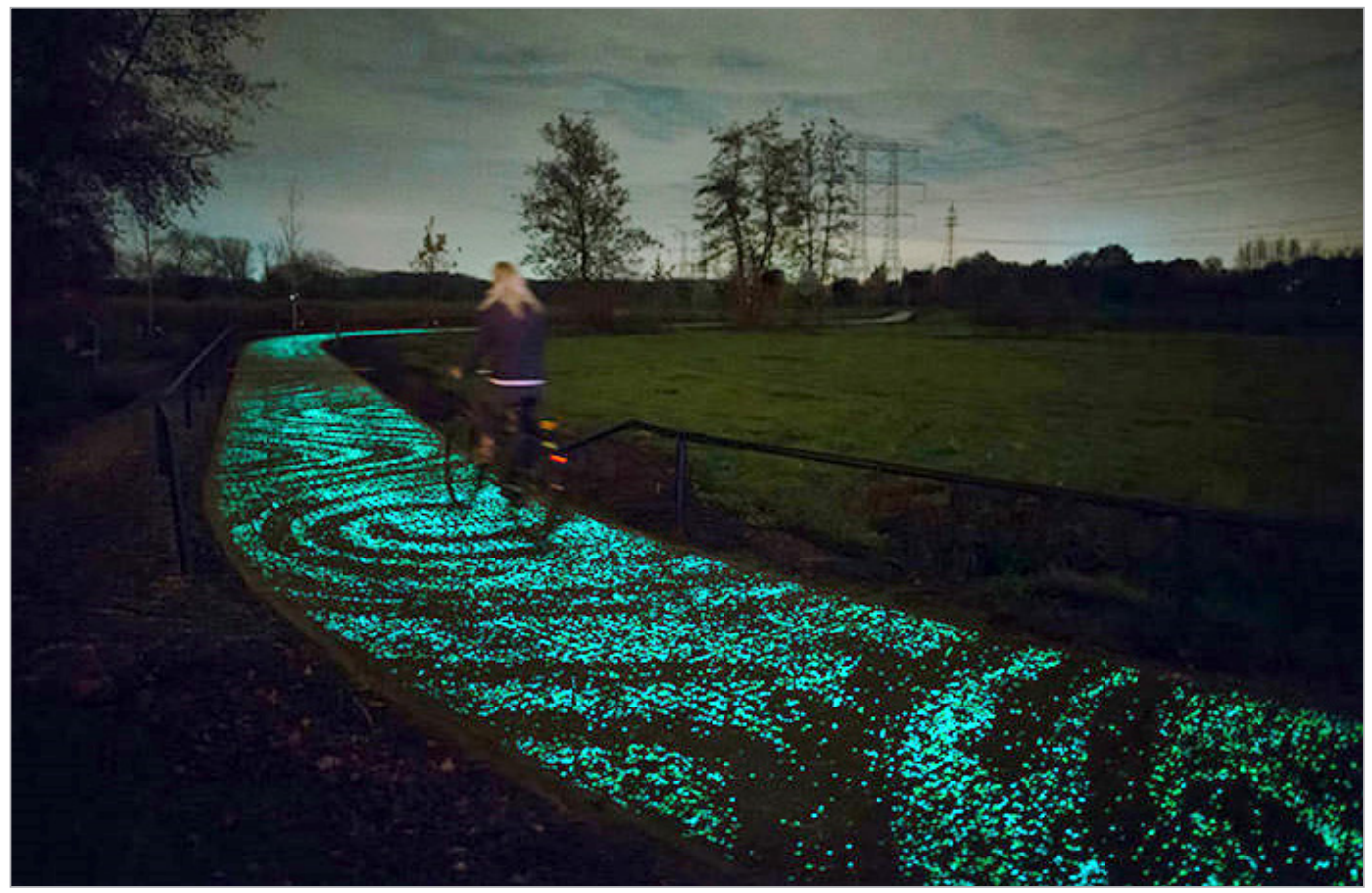

The layout Type 3 was selected for the installation of the energy harvesting structures in the park of Science Island museum because of the following reasons:

\section{Aesthetic Appeal}

Since the proposed project involves Landscape architecture, the third layout utilises different architectural aesthetic principles such as Order, Repetition, Spacing, Proportions in the placing of these structures throughout the Science Island Park.

\section{Extensive Utilisation}

The Science Island park area is used from one corner of the island to the other corner fully, with the PV Geodesic dome and Piezo-rain farm placed at the opposite ends of the Park. The location of these elements thus make the park fully exploited for the public to walk around.

The PV Energy calculation was carried out using EU Commission's PVGIS web Tool (Photovoltaic
Fig. 11

Luminescent Aggregate Concrete Road [Source:

Core Glow Product Gallery, Retrieved from http://www.coregravel. $\mathrm{ca} /$ products/core-glow/] 
Fig. 12

Monthly Average Solar radiation data for a year in Kaunas for South Direction, Lithuania. [Source: Image retrieved using PVGIS-CMSAF Solar Radiation Database from PVGIS Tool, http://re.jrc. ec.europa.eu/pvg_tools/ en/tools.html]

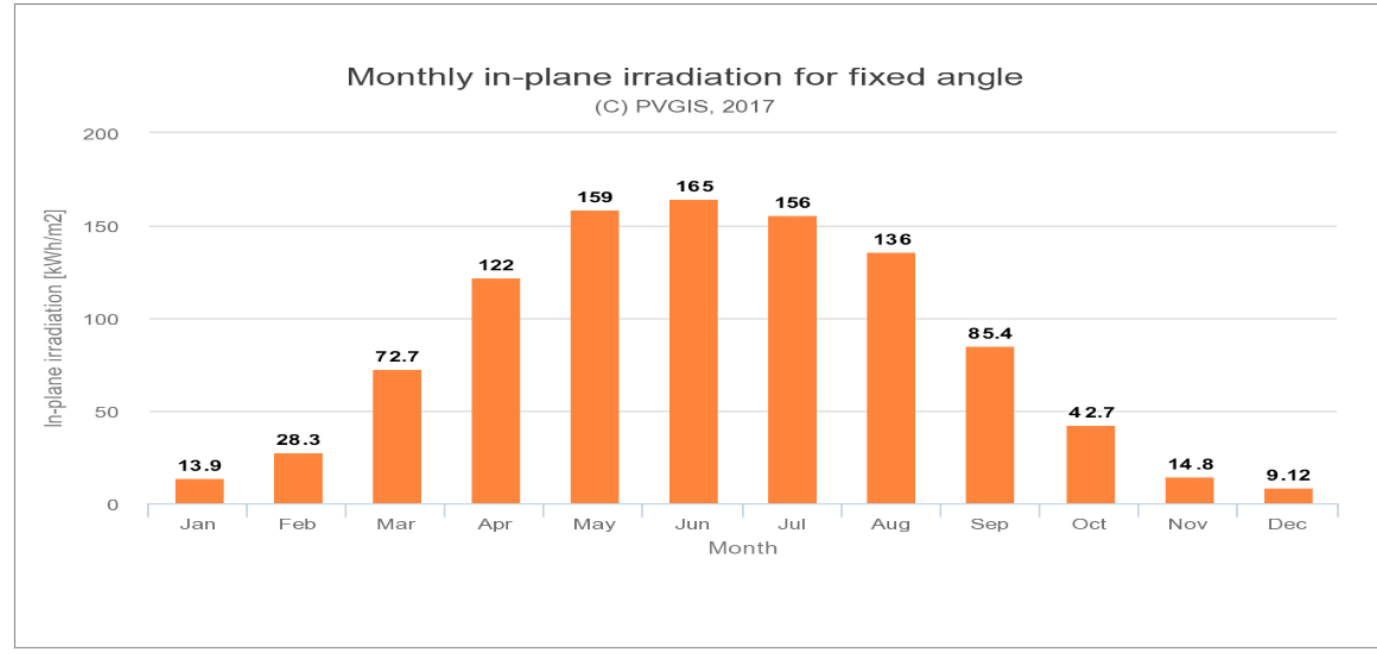

Geographical Information System [PVGIS], 2017). The tool also calculates the PV modules' optimum inclination and orientation for harvesting maximum electricity over the whole year. The tool outputs a local horizon outline graph based on the 2-km digital elevation model (Šúri, Huld, Dunlop, Albuisson, \& L., 2006) for the selected geographical location.

The combined data of medium direct and disperse radiation onto the horizontal surface in Kaunas under medium cloudiness is shown in Fig. 12. (Photovoltaic Geographical Information System [PVGIS], 2017)

Once the energy values are calculated for a module per annum, it is multiplied by the number of modules for the total energy output of the installed PV system.

The energy calculations of each of the different energy harvesting structures were calculated using PVGIS (Photovoltaic Geographical Information System [PVGIS], 2017) as follows:

\section{Solar Geodesic Dome}

The surface area of the $10 \mathrm{~m}$ diameter dome is $157.14 \mathrm{~m}^{2}$ while PV panel covers only for $118 \mathrm{~m}^{2}$. The angle of inclination could be anywhere from $35^{\circ}-45^{\circ}$ around the curved slope and horizontal at the peak. Data assumed for the calculation are as follows:

_ All panels are rectangular;

_ The optimized mean Angle is $40^{\circ}$;

- PV Module: PV Crystaline Silica 04TA_-16410989 (Onyxsolar, 2011).

Energy production is provided in Table 2.

\section{Photovoltaic Floor}

The PV floor is designed along the main path leading to the Science Island museum, proposed to be in the North Western end of the Island. Energy production is provided in Table 3.

\section{Photovoltaic Trees}

According to Sologic company, the total design capacity of a single unit of the suggested model is 800 Watts peak with $3.4 \mathrm{~kW}$ per day on average (Sologic, 2017). The electricity generated is in direct low voltage (DC).

The electricity produced from a single tree is $743 \mathrm{kWh}$ per annum. The electricity produced from all trees is $74,30 \mathrm{kWh}$ or $7.4 \mathrm{MWh}$ per annum. The calculation was made using PVGIS.

\section{Wind Energy Trees}

The wind data for Kaunas is shown in Fig. 13. 


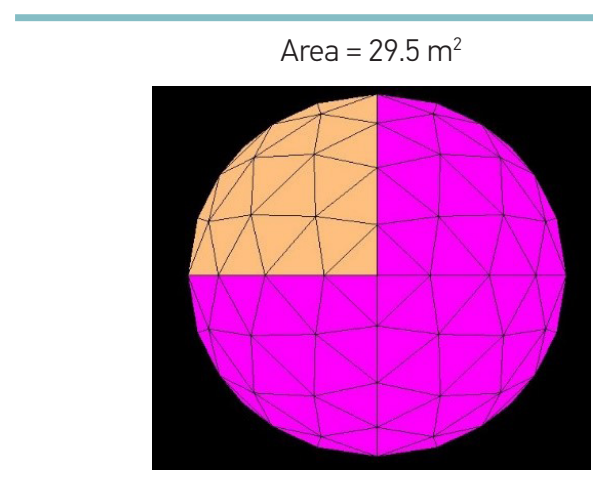

No. of Panels $=24$, Azimuth $=-0^{\circ}$ (North)

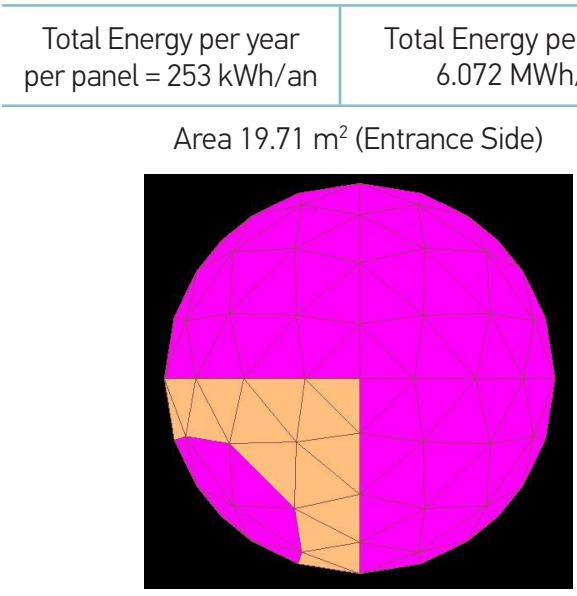

No. of Panels $=15$, Azimuth $=-90^{\circ}$ (West)

\begin{tabular}{c|c} 
Total Energy per year & Total Energy per year = \\
per panel = $392 \mathrm{kWh} / \mathrm{an}$ & $5.88 \mathrm{MWh} / \mathrm{an}$
\end{tabular}

Total Energy of the PV Geodesic Dome per year $=34 \mathrm{MWh} / \mathrm{an}$

Note: Number of Panels is taken for Triangular panels and not rectangular, All figures were designed using CADRE Geo 7

\begin{tabular}{c|c|c|c|c|c}
\hline $\begin{array}{c}\text { Energy Harvest- } \\
\text { ing Element }\end{array}$ & $\begin{array}{c}\text { Area of Solar } \\
\text { Panel }\left(\mathrm{m}^{2}\right)\end{array}$ & $\begin{array}{c}\text { Total Energy per year } \\
\text { per panel }(\mathrm{kWh} / \mathrm{an})\end{array}$ & $\begin{array}{c}\text { Total covering } \\
\text { Area }\left(\mathrm{m}^{2}\right)\end{array}$ & $\begin{array}{c}\text { No of } \\
\text { Units }\end{array}$ & $\begin{array}{c}\text { Total Energy per } \\
\text { year }(\mathrm{MWh} / \mathrm{an})\end{array}$ \\
\hline PV Floor & 0.36 & 13.5 & 300 & 833 & 11.2455 \\
\hline
\end{tabular}

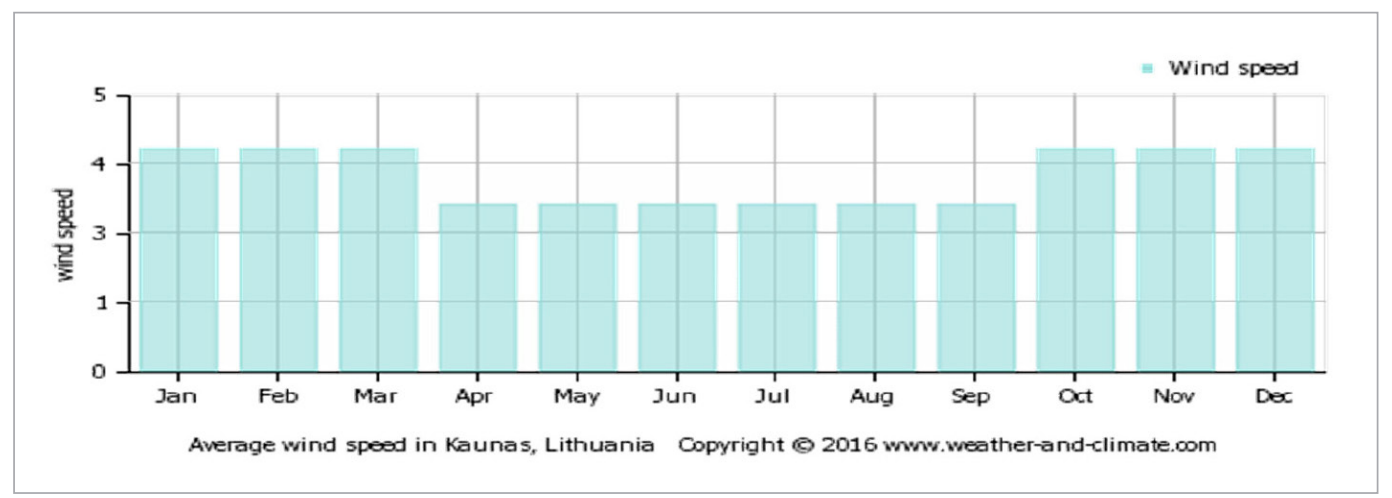

\section{Table 2}

Energy Production Calculation for PV Geodesic Dome

\section{Table 3}

Energy Production Calculation for PV Floor and PV Geodesic Dome

\section{Fig. 13}

Mean monthly wind speed at a standard height of $10 \mathrm{~m}$ above Ground level (meters per second) [Source: Image retrieved from https://weatherand-climate.com/ average-monthly-Windspeed,Kaunas,Lithuania] 
Table 4

Energy Production Calculation for Wind Energy Trees

Table 5

Comparison of Energy production by proposed Modules

Table 6

Cost Overview of Energy Harvesting Elements

The wind energy production is presented in Table 4.

It should be noted that the wind energy is calculated for a standard wind speed of $2 \mathrm{~m} / \mathrm{s}$ and an activation threshold of $1.3 \mathrm{~m} / \mathrm{s}$.

\begin{tabular}{c|c|c|c|c|}
\hline $\begin{array}{c}\text { Installed } \\
\text { capacity of a } \\
\text { single tree }\end{array}$ & $\begin{array}{c}\text { Total } \\
\text { number of } \\
\text { Trees }\end{array}$ & $\begin{array}{c}\text { Total Capacity } \\
\text { of installed } \\
\text { trees }\end{array}$ & $\begin{array}{c}\text { Estimated average pro- } \\
\text { duction of a single tree in } \\
\text { a year }\end{array}$ & $\begin{array}{c}\text { Estimated average produc- } \\
\text { tion of installed trees in a } \\
\text { year }\end{array}$ \\
\hline $4.1 \mathrm{~kW}$ & 10 & $41 \mathrm{~kW}$ & $2400 \mathrm{kWh}$ & $24 \mathrm{MWh}$ \\
\hline
\end{tabular}

\section{Piezo Rain Farm}

The energy produced from a Piezo rain farm in comparatively and considerably lower than that of the Solar Energy Harvesting and Wind Energy Harvesting. The sole purpose of the Piezo rain farm is for fun and play smaller led lights for children who visit the park. This proposed idea involves

\begin{tabular}{l|c|c}
\multicolumn{1}{c|}{$\begin{array}{c}\text { Energy Harvesting } \\
\text { Element }\end{array}$} & No of Units & $\begin{array}{c}\text { Total Energy per year } \\
\text { in MWh/an }\end{array}$ \\
\hline PV Floor & 833 PV floor tiles & 11.245 \\
\hline PV Geodesic Dome & 97 PV panels & 34 \\
\hline PV Tree & 10 & 7.4 \\
\hline Wind Energy Tree & 10 & 24 \\
\hline \multicolumn{2}{c|}{ Total } & 83.645 \\
\hline
\end{tabular}
further research for energy calculations.

The energy calculations of all the Energy harvesting modules excluding the Piezo rain farm are summarised in Table 5 .

Based on the results, it could be observed that by utilizing the different proposed energy harvesting elements, approximately $84 \mathrm{MWh}$ of energy can be produced in the Science Island museum park per year. The calculated figures may vary depending on the final technology selection and site design.

The Science Island Museum's building cost is estimated at 25 million Euros (Malcolm Reading Consultants, 2017).

The total cost of the Science Island Park project is 1.2 Million Euros. The Construction cost is estimated based on the work schedule. This includes the cost of each Energy harvesting element, labour cost, construction materials cost. The details of the cost of each of the energy harvesting element is presented in Table 6 .

If the number of solar trees and wind trees are reduced, the total cost of the project will be reduced significantly. This project proposal is made as an idea that might be presented to the City council of Kaunas Municipality.

The Kaunas City Council had proposed creating a Science Island museum on the Nemunas River Island area besides the Žalgiris Sports and Entertainment Arena. The paper propose to utilizing the park area around the Science museum in the Island by installing innovative energy harvesting structures incorporated into Landscape Architecture. Three different layouts of the installations 
around the park area were suggested and the third layout was selected to be the most functionally appealing. The different innovative energy harvesting elements proposed mainly were PV Geodesic Dome, PV Floor, PV trees, Wind Energy harvesting Trees and Piezoelectric rain farm. Besides these elements, an electricity free luminescent pavement with glow aggregates was also presented. The total energy produced from the proposed Energy harvesting structures is estimated to be around $84 \mathrm{MWh}$. The total cost of the Project is about 1.2 million Euros. With the Kaunas City council's already announced budget of 25 million Euros for the Science Museum, the total cost of the project incorporating Innovative Energy Harvesting Exposition Park would be 26.2 million Euros.

The authors would like to thank the Representatives of the following Companies for their valuable information on their products:

- L'Aeroleaf ${ }^{\circledR}$ and WindTree (Arbre à Vent ${ }^{\circledR}$ ) are products of NewWind, 130, rue de Lourmel 75015 Paris - France. NewWind reserves all Rights of their products.

- Walkable PV Floor is a product of ONYX SOLAR', Spain (Avila), C/ Rio Cea 1, 46 - 05004, Phone:+34920210050, info@onyxsolar.com. ONYX SOLAR reserves all Rights of its product.

CORE Glow ${ }^{\mathrm{TM}}$ pebbles and stones are the products of CORE Glow ${ }^{\mathrm{TM}}$, CORE Systems (Head Office) - E-mail: info@coregravel.ca or Phone: 1.855.777.2673 (CORE). CORE Glow ${ }^{\mathrm{TM}}$ reserves all Rights of their products.

eTree is a product of Sologic, sol-logic Ltd., 311 P.O. Benyamina, Phone: 077-4144048, Fax : 0774241913, Cellular : 054-8113868Email : info@sol-logic.com

SOLARDOME ${ }^{\circledR}$ PRO is a product of SOLARDOME ${ }^{\circledR}$, Solardome Industries Limited, Unit 4, Yeomans Ind Park Test Lane, Nursling, S016 9JX, United Kingdom. SOLARDOME ${ }^{\circledR}$ reserves all Rights of its product.

All Photovoltaic Calculations were made using PVGIS5, PVGIS (c) European Communities, 2001-2012.

PV Geodesic Domes were designed using CADRE Geo 7 (Evaluation version), AutoCAD 2018.

\section{Acknow- ledgment}

Chaturvedi, P., \& Kumar, D. (2013). Piezoelectric energy harvesting from vibration induced deformation of floor tiles. National Power Electronics Conference (NPEC-2013) (pp. 1-6). Kanpur: ResearchGate. Retrieved March 2, 2014, from https://www.researchgate.net/publication/264048738_Piezoelectric_Energy_Harvesting_from_Vibration_Induced_ Deformation_of_Floor_Tiles

Core Glow. (2017). Products. Retrieved from coregravel.ca: http://www.coregravel.ca/products/core-glow/

Dhingra, P., Biswas, J., Prasad, A., \& S., S. (2012). Energy Harvesting using Piezoelectric Materials. Special Issue of International Journal of Computer Applications (0975 - 8887) (pp. 38-42). Manipal: International Conference on Electronic Design and Signal Processing (ICEDSP) 2012. Retrieved from research. ijcaonline.org/icedsp/number4/icedsp1037.pdf

DiMari, A. (2010, n.a. n.a.). Urban Field. Retrieved April 20, 2017, from anthonydimari.com: http://anthonydimari.com/

Fonash, S. J. (2010). Solar Cell Device Physics (Second ed.). n.a., United States of America: Elsevier. Retrieved November 15, 2017

Glowee. (2017). Why should we develop a biological source of light? Retrieved November 15, 2017, from www.glowee.eu: http://www.glowee.eu/

Hossain, M. S., \& Li, B. (2016). Renovation of nzcb in a poor solar irradiation zone: an investigative case study of residential buildings in chongqing urban areas. INTERNATIONAL JOURNAL OF ENERGY AND ENVIRONMENT, 7(1), 49-60. doi:https://www.ijee. ieefoundation.org/vol7/issue1/IJEE_04_v7n1.pdf

J. Dicken, P. M., Stoianov, I., \& Yeatman, E. (2012, April 3). Power-Extraction Circuits for Piezoelectric Energy Harvesters in Miniature and Low-Power Applications. (P. M. J. Dicken, I. Stoianov, \& E. Yeatman, Eds.) IEEE TRANSACTIONS ON POWER ELECTRONICS, 27(11), 4514 - 4529. https://doi.org/10.1109/ TPEL.2012.2192291

Kumar, D., Chaturvedi, P., \& Jejurikar, N. (2014). Piezoelectric Energy Harvester Design and Power Conditioning. 2014 IEEE Students' Conference on Electrical, Electronics and Computer Science (pp. 1-6). Vidisha: IEEE. Retrieved from http://ieeexplore. ieee.org/stamp/stamp.jsp?arnumber=6804491. https://doi.org/10.1109/SCEECS.2014.6804491

Lietuvos Energetikos Institutas. (2010, April 9). Opet/Res/solar_energy.htm. Retrieved November 9 , 
2017, from www.lei.lt: http://www.lei.lt/Opet/Res/ solar_energy.htm

Majeed, A. (2015). Piezoelectric Energy Harvesting for Powering Micro Electromechanical Systems (MEMS). Journal of Undergraduate Research 5, 1 , 17-21. Retrieved from firstmonday.org/ojs/index. php/JUR/article/download/7534/6028. https://doi. org/10.5210/jur.v8i1.7534

Malcolm Reading Consultants. (2017, June 27). Competitions. Retrieved February 25, 2017, from malcolmreading.co.uk: https://competitions.malcolmreading.co.uk/scienceisland/contest

Mertens, K. (2014). Photovoltaics Fundementals, Technology and Practice (First ed.). (G. Roth, Trans.) n.a., Malasiya: John Wiley \& Sons Ltd. Retrieved November 15, 2017

Ministry of Energy of the Republic of Lithuania. (2017, June 7). sectoral-policy/renewable-energy-sources. Retrieved November 15, 2017, from enmin.lrv.lt/en: https://enmin.lrv.lt/en/sectoral-policy/renewable-energy-sources

Newwind. (2017). Innovations. Retrieved from newwind.fr/en: http://www.newwind.fr/en/innovations/

Onyxsolar. (2011). Resources. Retrieved April 15, 2017, from www.onyxsolar.com: http://onyxsolardownloads. com/docs/ALL-YOU-NEED/Technical_Guide.pdf

OnyxSolar. (2017). Constructive Solutions. Retrieved from onyxsolar.com: http://www.onyxsolar.com/ walkable-photovoltaic-roof.html

Photovoltaic Geographical Information System [PVGIS]. (2017). pvg_tools/en/tools. Retrieved November 18, 2017, from re.jrc.ec.europa.eu: http:// re.jrc.ec.europa.eu/pvg_tools/en/tools.html

photovoltaic-software.com. (2017). Principle and ressources. Retrieved from photovoltaic-software.com: http://photovoltaic-software.com/PV-solar-energy-calculation.php

Schreiber, M. (2016, August 23). Quartz. Retrieved from qz.com: https://qz.com/763715/wind-treesmini-turbines-that-can-power-homes/

SOLARDOME ${ }^{\circledR}$. (2017). Dome Range. Retrieved from solardome.co.uk: http://www.solardome. co.uk/products/pro/

SOLARDOME ${ }^{\circledR}$. (2017). Dome Range. Retrieved from solardome.co.uk: http://www.solardome. co.uk/products/glasshouses/paradise/

Sologic. (2017). The Solar Tree Project. Retrieved from sol-logic.com ; solargiving.com: http://sol-logic.com/etree/ ; http://solargiving.com/homepage/

Šúri, M., Huld, T., Dunlop, E., Albuisson, M., \& L. W. (2006). Online data and tools for estimation of solar electricity in africa: the pvgis approach. 21st European Photovoltaic Solar Energy Conference and Exhibition ( $\mathrm{p}$. 3). Dresden: n.a. doi:http://re.jrc.ec.europa.eu/pvgis/ doc/paper/2006-Dresden_6A0.5.1_Suri_etal.pdf

The Engineering ToolBox. (2017). Wind Power. Retrieved from engineeringtoolbox.com: http://www. engineeringtoolbox.com/wind-power-d_1214.html

The Royal Academy of Engineering. (n.a., n.a. n.a.). publications/other/23-wind-turbine. doi:www.raeng. org.uk/publications/other/23-wind-turbine

Torres, E. O., \& Rincón-Mora, G. A. (2005, June 30). Energy-harvesting chips and the quest for everlasting life. Retrieved from eetimes.com: http://www. eetimes.com/document.asp?doc_id=1273025

weather-and-climate.com. (2017). Lithuania > Climate Kaunas > Sunshine. Retrieved from weather-and-climate.com: https://weather-and-climate.com/average-monthly-hours-Sunshine,Kaunas,Lithuania weather-and-climate.com. (2017). Lithuania > Climate Kaunas > Wind speed. Retrieved from weather-and-climate.com: https://weather-and-climate.com/average-monthly-Wind-speed,Kaunas,Lithuania

Yildiz, F. (2009). Potential Ambient Energy-Harvesting Sources and Techniques. (C. V. Schwab, Ed.) The Journal of Technology studies, 35(1), e-journal. doi: https://doi.org/10.21061/jots.v35i1.a.6

\section{About the authors}

\section{HARIHARASUBBU BALAMOORTHY \\ Master Student}

Faculty of Civil Engineering and Architecture, Kaunas University of Technology

Main Research Area

Construction Technology

\section{Address}

Studentu st. 48, LT-51367 Kaunas, Lithuania E-mail: Hariharasubbu.balamoorthy@ktu.edu, dan23.bhhs@gmail.com

\section{RASA APANAVICIENE}

Assoc. Professor

Faculty of Civil Engineering and Architecture, Department of Civil Engineering Technologies

\section{Main Research Areas}

Economics and Management of Architectural Design, Construction Project Management, Artificial Intelligence

\section{Address}

Studentu st. 48, LT-51367 Kaunas, Lithuania Tel. +370 37300479

E-mail: rasa.apanaviciene@ktu.lt 